\title{
Nuevos enfoques para el estudio de los monumentos megalíticos de Europa Occidental
}

Chris Scarre, Department of Archaeology, Durham University

Traducción: Gary Scowcroft y M Mª Isabel Fernández Medina 


\section{Resumen}

Los monumentos megalíticos son probablemente la herencia más impresionante de las comunidades prehistóricas de Europa occidental. La asociación frecuente del folclore con los acontecimientos o seres humanos sobrenaturales o legendarios atestigua el poder que han seguido ejerciendo hasta los últimos tiempos. Estos monumentos toman una variedad de formas, que incluyen piedras de pie, en círculo y alineadas, así como las cámaras megalíticas que contienen a menudo enterramientos y que están así mismo enterradas bajo montones de tierra o de piedras. El carácter peculiar de los monumentos megalíticos es el uso de grandes bloques tomados de campos de rocas o de afloramientos de roca. Los más grandes de estos monumentos habrían requerido del trabajo cooperativo de millaresde trabajadores, existiendo a veces evidencia de que traían gente y materiales desde una distancia considerable. Anteriormente se buscaba un sólo origen para los monumentos megalíticos que se consideraron como testimonio de la expansión de colonos o de misionarios mediterráneos. Los métodos científicos de datación desde los años 60 han eliminado estos modelos antiguos, pero nos dejan con el desafío de explicar los monumentos megalíticos de nuevas maneras. Una parte importante de estos nuevos enfoques es comprender la forma en la que los monumentos megalíticos adoptaron materiales naturales y transformaron los paisajes en los que fueron construidos. La importancia simbólica de las piedras individuales es también crucial en una nueva comprensión de estas estructuras enigmáticas.

\section{Palabras clave}

Arqueología I Cosmovisión I Edad del cobre I Edad del bronce Europa occidental I Megalitismo I Monumentos megalíticos I Neolítico I Paisaje I Patrimonio arqueológico

\section{INTRODUCCIÓN}

Los monumentos megalíticos se encuentran entre los más impresionantes restos que nos han legado las sociedades prehistóricas. Los visitantes de Stonehenge en Inglaterra meridional, de Carnac en el sur de Bretaña, o de la Cueva de Menga en Antequera, no pueden dejar de sentirse intrigados por las enormes proporciones de los bloques de piedra que se utilizaron en su construcción, y lo maravilloso de estos logros es amplificado por la gran antigüedad de las estructuras que en general tienen más de 4000 años y, en algunos casos, más de 6000. No es extraño que en la imaginación popular se hayan asociado con seres legendarios y míticos. Por ejemplo, en un texto del siglo XII se afirma que Stonehenge fue transportado desde Irlanda por Merlin, el mago de leyenda del Rey Arturo. El círculo de piedras 'Merry Maidens' (las felices doncellas) en Cornualles representa tradicionalmente a un grupo de muchachas jóvenes convertidas en piedra por bailar sacrílegamente en el Sabbath. Popularmente se creía que el menhir de Saint-Samson-sur-Rance en la Bretaña del norte bloqueaba una de las puertas del Infierno (imagen 2). Muchos de los monumentos megalíticos de España y Portugal se atribuyen a los moros. Los mensajes son claros y recurrentes: los megalitos son obra de gente no cristiana o precristiana, están con frecuencia vinculados a prácticas mágicas, y se asocian también con una advertencia, que se trata de lugares investidos de un poder misterioso y quizás amenazador.

El término "monumento" que es de uso general para describir las estructuras megalíticas tiene significados múltiples. Deriva en última instancia del latín monumentum ("algo que recuerda"), que está relacionado con el verbo monere ("recordar" o "advertir"). En lengua inglesa, sólo a principios de siglo XVII empezó este término a referirse a una estructura construida para conmemorar a una persona o evento, y más tarde se tomó en el sentido más amplio de algo de gran tamaño, como la palabra "monumental". En el contexto de las estructuras megalíticas hace hincapié en 


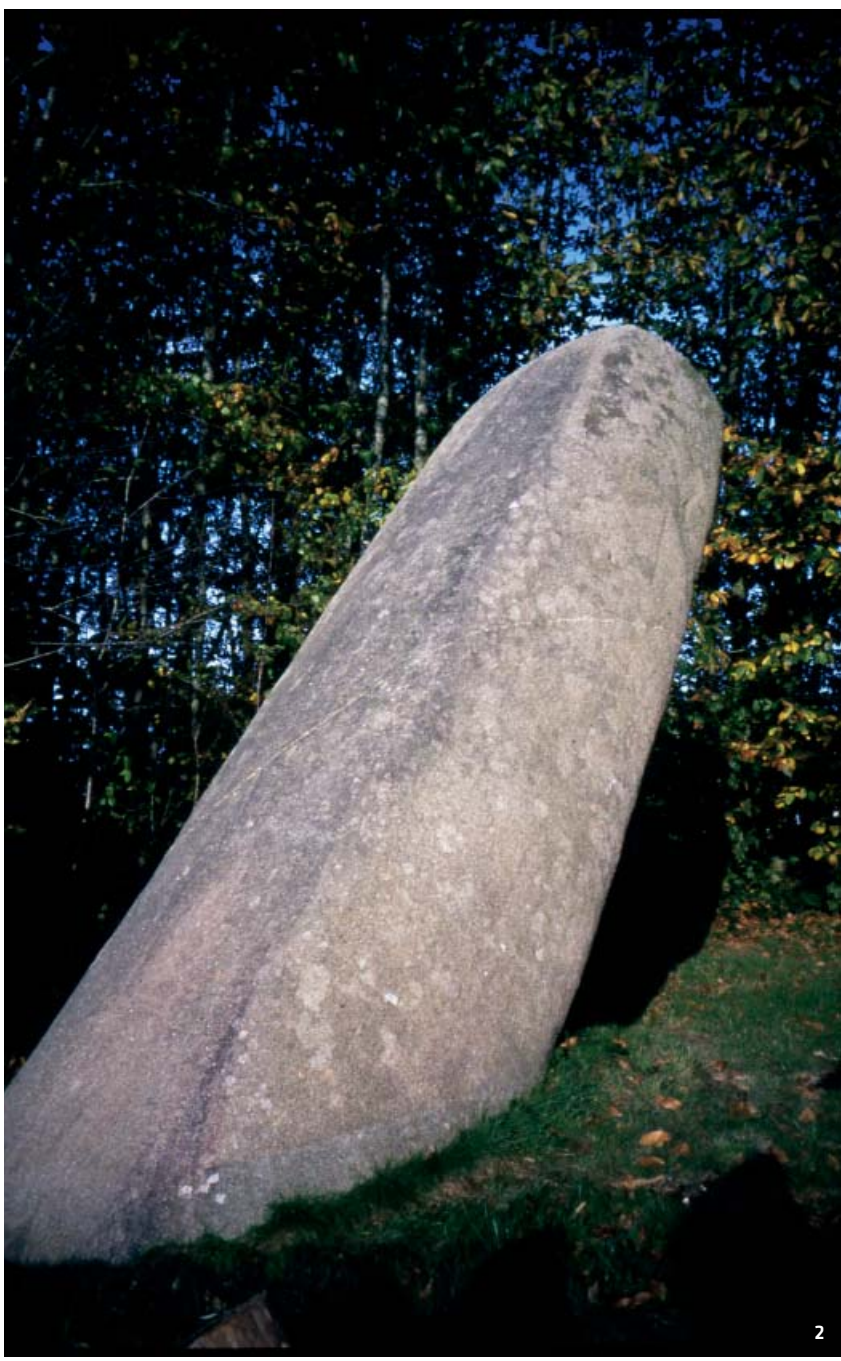

la forma y tamaño -su escala "monumental"- pero el componente "mnemotécnico" sobrevive. Los monumentos megalíticos son estructuras duraderas, y recuerdan a las sociedades antiguas. Igualmente, pueden generar el tipo de memorias o tradiciones de folclore "falsas" al que se ha hecho referencia más arriba. Paradójicamente, también pueden estar asociados a actos conscientes de olvido, ya que los monumentos megalíticos que vemos hoy pueden cubrir y ocultar los sitios de anteriores estructuras de madera que fueron intencionadamente quemados, o pueden incluir y ocultar piedras que fueron colocadas originalmente en otro lugar, como parte de estructuras de diversas clases.

El término "megalito", procedente de las palabras griegas megas o grande y lithos o piedra, es un término de origen más reciente, inventado en el siglo XIX, para describir monumentos de grandes losas de piedra sobre las que ya habían escrito los historiadores y los anticuarios siglos atrás. Algunos arqueólogos han puesto en duda su exactitud y utilidad. Sin duda, los monumentos megalíticos son realmente sólo una rama de una familia más grande. Esta observación se aplica particularmente a las tumbas megalíticas, en las que las grandes losas de piedra se asocian frecuentemente con el aparejo de mampostería que rellena los huecos entre los bloques más grandes. Otras tumbas compuestas en su totalidad de paredes de mampostería se incluyen regularmente (aunque de forma inexacta) en la misma categoría general, incluso cuando las tumbas "megalíticas" y las "no megalíticas" puedan ser coetáneas y encontrarse juntas unas a otras dentro de un mismo conjunto monumental. Claramente son variantes de una tradición única. Lo mismo se aplica a determinadas tumbas hipogeas, que copian las formas y diseños de los monumentos megalíticos, y de las que, una vez más, existen ejemplos en los que se combinan técnicas hipogeas y megalíticas.

Sin embargo, la confusión entre monumentos megalíticos y no megalíticos dentro de la misma categoría no oculta lo que es, sin duda, una de las características cruciales de estos monumentos. ¿Cuál es el sentido del elemento "megalítico", es decir, el uso de piedras de tamaño extravagante? Al responder a esta pregunta, debemos observar primero que los grandes monumentos megalíticos no se restringen a Europa occidental, sino que se encuentran en partes muy dispersas del mundo: en el Cáucaso, en el sur de la India, en Senegambia, Colombia, y en las islas de Asia Sur-Oriental, por nombrar sólo algunas, por no olvidar las estatuas mundialmente famosas de la Isla de Pascua, que son megalíticas en virtud de su carácter monolítico y grandes dimensiones. De esta lista, es evidente que el concepto de monumento "megalítico" no tiene una sola fuente de origen, sino que ha sido una característica recurrente de la actividad humana en diferentes periodos y en diferentes lugares. Lo que tienen en común estas tradiciones megalíticas es el uso de grandes bloques de piedra para crear estatuas o estructuras. Combinan la durabilidad de la piedra con su tamaño y peso para transmitir una imagen potente y evocadora de poder.

\section{TAMAÑO Y SOCIEDAD}

Dentro de la tradición megalítica de Europa occidental, los bloques individuales de piedra van desde ejemplos modestos que pesan solamente dos o tres toneladas a los monolitos enormes que requerían el esfuerzo combinado de cientos o miles de personas para su desplazamiento y erección. Las piedras más grandes de Stonehenge, las de los "trilitos" centrales, miden más de 9 metros de altura (sus bases están todavía enterradas en los cimientos excavados en la creta) y pesan aproximadamente 40 toneladas. Su origen exacto es desconocido, aunque tradicionalmente se ha pensado que proceden de Marlborough Downs, a unos $30 \mathrm{~km}$ al norte, 


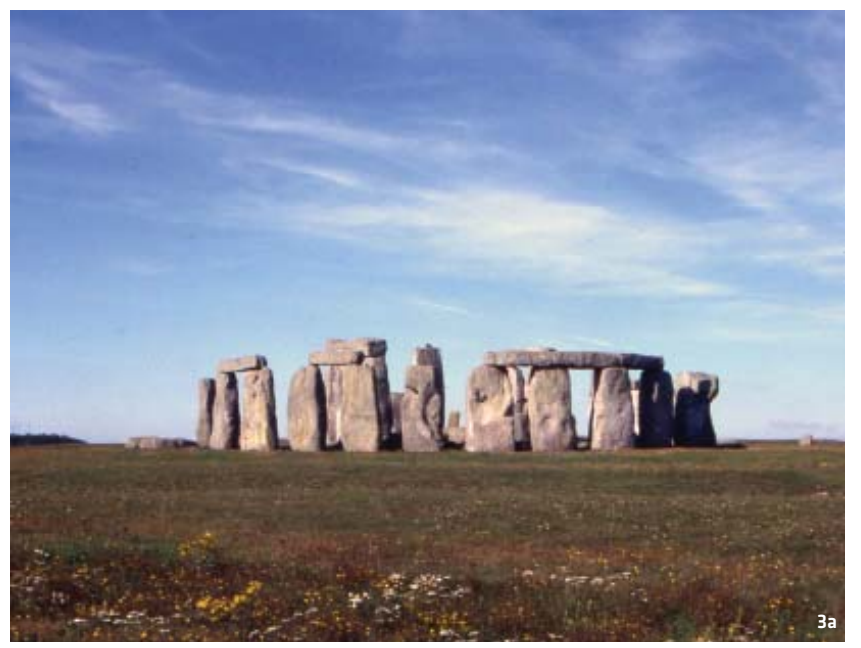

donde bloques naturales, similares aunque mucho más pequeños, aún se encuentran desperdigados por la superficie. Es más probable, quizás, que en el período anterior a que el paisaje natural de Stonehenge fuera despejado de tales bloques naturales, éstos vinieran de lugares mucho más cercanos al sitio. Cualquiera que fuera la distancia, los experimentos llevados a cabo en el desplazamiento de réplicas de piedras de 40 toneladas a través de este terreno indican que debieron necesitarse equipos de 130 personas o más para arrastrar las piedras, que irían atadas con correas a patines de madera a lo largo de raíles de madera engrasados (RICHARDS Y WHITBY, 1997). Es difícil asegurar que esa fuera la técnica que se utilizaba realmente. En un experimento similar en Francia occidental, una réplica de 32 toneladas que requería 200 personas para moverla tirada por cuerdas pudo ser impulsada por sólo 10 personas empleando un sistema de rodillos con "remos" encajados. En el otro extremo de la escala, piedras de sólo 2 ó 3 toneladas pueden haber sido manipuladas por equipos de sólo media docena de personas, lo que se situaría dentro de la capacidad de una sola comunidad o incluso de los habitantes de una pequeña granja. Las piedras más grandes, sin embargo, deben haber exigido el trabajo cooperativo de varios cientos de personas o más.

En una época en la que las densidades de población en Europa occidental eran relativamente bajas, la construcción de grandes monumentos hubiera hecho necesaria la reunión de gente y de comunidades desde amplias áreas. La idea que puede explicar mejor ese proceso es la peregrinación. Ciertos lugares, tal vez algunos monumentos, se convirtieron en lugares de energía sagrada que atraían a gente de todas partes. Los círculos de Stonehenge y de Avebury ejemplifican el proceso. Ambos tienen grandes piedras individuales que habrían exigido un gran número de personas para moverlas y levantarlas. Aunque los paisajes vecinos hubieran estado plagados de bloques de sarsen (are-

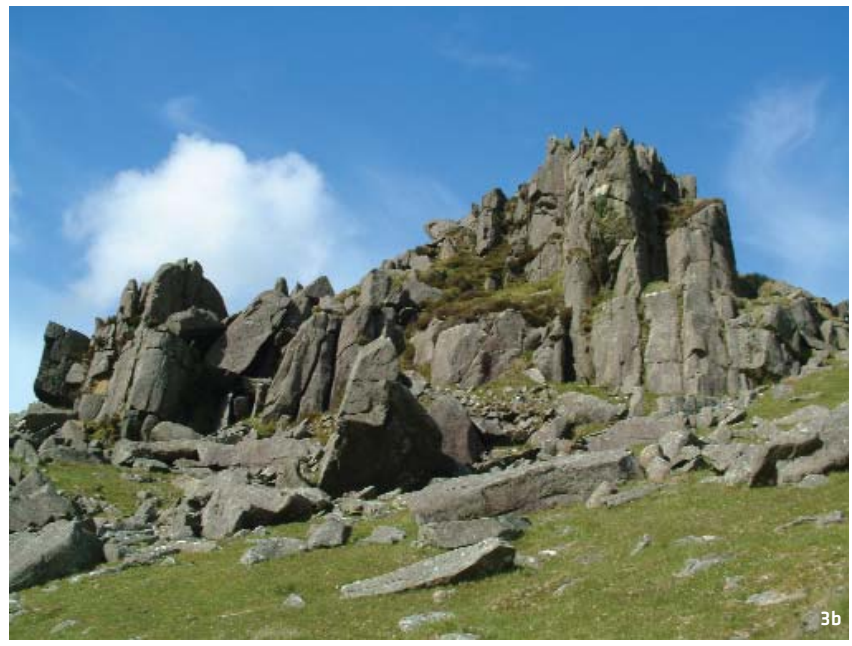

nisca), y por tanto el material hubiera estado disponible más a mano de lo que se creía tradicionalmente, el esfuerzo necesario para mover y levantar las piedras más grandes (y en el caso de Stonehenge, tallarlas para darles forma) habría estado fuera del alcance de la capacidad individual de una comunidad cualquiera. Como hemos visto, se ha estimado que las piedras más grandes en Stonehenge pesan 40 toneladas; la más grande en Avebury, la llamada Cove Stone, supera incluso a esta piedra con en torno a 60 toneladas. Las piedras más pequeñas en Stonehenge también proporcionan evidencias de que el carácter sagrado de estos grandes monumentos se extendía por amplias regiones. Aunque estas piedras más pequeñas, llamadas bluestones (piedras de dolerita), pesan menos de 2 toneladas, el estudio petrológico ha demostrado que vinieron de las colinas de Preseli en el Suroeste de Gales, a más de 200 km de distancia. Las bluestones no son especialmente llamativas en sí mismas, pero se originaron en un lugar de afloramientos imponentes con bloques de piedra sueltos alrededor de la base de un acantilado (imagen 3 a y b). Es muy posible que las colinas de Preseli fueran consideradas un lugar sagrado por los constructores de Stonehenge, pero el movimiento del material a tan largas distancias indica que los monumentos como Stonehenge fueron venerados y respetados mucho más allá del área local (DARVILL, 2006). Las bluestones pudieron haber sido traídas a su lugar definitivo como parte de una tradición de peregrinación a larga distancia. La capacidad de Stonehenge para atraer gente (y no sólo materiales) de lejos ha sido demostrada por los recientes descubrimientos. A dos kilómetros al sureste, un rico enterramiento campaniforme contenía los restos mortales del llamado "arquero de Amesbury". El análisis isotópico de sus dientes reveló que este individuo había vivido en Europa continental hasta la edad adulta, en la que debió viajar al área de Stonehenge. Otro sepulcro, el de "los arqueros de Boscombe", contenía los restos de seis personas (cuatro varones adultos, 
dos adolescentes), cuyas firmas isotópicas sugirieron su origen al oeste de Gran Bretaña, posiblemente en la misma zona del sudoeste de Gales, de donde preceden las bluestones (SCARRE, 2007).

El concepto de peregrinación también puede explicar el tamaño y la sofisticación de los monumentos megalíticos en otras áreas de Europa occidental. Una de las mayores concentraciones de tales monumentos se encuentra en el área de Morbihan en la Bretaña meridional. Entre los monumentos de Morbihan existen túmulos funerarios enormes tales como el Tumulus de Saint-Michel (que mide $120 \mathrm{~m}$ de largo, $60 \mathrm{~m}$ de ancho y $10 \mathrm{~m}$ de alto, con espacio suficiente para acomodar una capilla del siglo XVII en su cumbre) y las filas de piedra de Carnac, especialmente las de Kerzehro, Kermario y Le Ménec, cada una de las cuales se extiende por más de un kilómetro y están formadas por más de 1000 menhires individuales. En términos de tamaño, sin embargo, el primero es el Gran Menhir de Brisé en Locmariaquer (imagen 4). Este enorme monolito ahora se encuentra roto en cuatro fragmentos, pero cuando estaba intacto habría Ilegado a 20 metros de alto, el menhir más grande jamás erigido por las comunidades prehistóricas en Europa occidental. Parece haber sido también uno de los primeros. Aunque la datación de menhires individuales es difícil y a menudo problemática, en el caso del Gran Menhir Brisé sabemos que se colocó originalmente en posición vertical (se ha localizado la fosa de cimentación) y que se cayó hacia finales del quinto milenio, puesto que la superficie sobre la que descansa hoy día contiene material de ese período. El Gran Menhir Brisé presenta otras tres características destacadas. Primero, sus superficies fueron talladas cuidadosamente golpeándolas repetidamente y limándolas con mazos de piedra para producir una superficie afacetada. Además, en una cara aparece un dibujo que algunos han interpretado como un cachalote, y que fue trabajado en alto relieve. La segunda característica destacable del Grand Menhir Brisé es su tamaño. Se ha estimado que las piedras más grandes de Stonehenge pesan 40 toneladas: cuando fue terminado, el Grand Menhir Brisé pesaba aproximadamente 280 toneladas. El reto de transportar y levantar un monolito tan inmenso sólo con la tecnología premoderna habría sido extraordinario, hasta el punto de que sea difícil entender cómo se logró con éxito. El logro es aún mayor teniendo en cuenta que la tercera característica más importante del Grand Menhir Brisé (un bloque de ortogneis) es que fue trasladado desde una distancia de por lo menos $10 \mathrm{~km}$ hasta el lugar donde fue erigido (LE ROUX, 1997). El transporte y el levantamiento de tal piedra habrían exigido el esfuerzo cooperativo de varios miles de personas, tal vez reunidas desde una amplia área del noroeste de Francia. Su caída y fractura, resultado probablemente de un terremoto, debió causar una conmoción en toda la región.

El cimiento en el cual el Gran Menhir Brisé se colocó originalmente se encuentra al final de una fila de agujeros de piedra, marcando el sitio de lo que fue un alineamiento. Las piedras restantes fueron extraídas y des- menuzadas, siendo por lo menos algunos de los fragmentos resultantes reciclados y reutilizados en sepulcros de corredor en los alrededores. El alineamiento de 18 agujeros para calzar menhires, más el propio Grand Menhir Brisé, parece empequeñecerse sin embargo por las largas hileras de piedra de Kerzehro, de Kermario y de Le Ménec (imagen 5). Las piedras individuales en estos alineamientos kilométricos son básicamente más pequeñas que las del Gran Menhir Brisé, y habrían requerido de pocas personas para transportarlas y erigirlas, pero lo que les falta en tamaño es compensado por su gran número. De nuevo se puede pensar que las filas de piedras marcan localizaciones sagradas que eran quizás centros de peregrinación. Las mismas comunidades que se habían reunido para levantar el Gran Menhir Brisé pudieron haber vuelto año tras año para levantar las alineaciones de Carnac. El carácter progresivo de estos proyectos a veces se pone de manifiesto por la disposición de las filas de piedras, o se puede documentar con el estudio cuidadoso de cada una de las piedras. Las largas filas de piedras de Le Ménec terminan en su extremo occidental (y originalmente también en el oriental) en un recinto oval delimitado por piedras verticales (imagen 6). La entrada original al recinto oval occidental en su lado este se abre entre dos de las filas de piedras en mitad de las alineaciones. Se ha sugerido que éste era el diseño original, con una avenida simple de dos filas que proporcionaba una vía procesional que llevaba al recinto cuesta arriba. Por el contrario, las filas de piedras que flanquean esta avenida central en el lado norte se dispersan tanto que, si se hiciera una proyección, perderían la dirección hacia el recinto (BURL, 1993). Puede ser que estas filas suplementarias fueran agregadas progresivamente como acto de veneración por los peregrinos o los visitantes a lo largo de un período de décadas o de siglos. La multiplicación de las filas de piedras de Carnac, donde 10 o más filas de piedras están hoy en paralelo a través del paisaje, puede, por lo tanto, no ser parte del diseño original, sino resultado de una serie de modificaciones posteriores.

La peregrinación pudo, por lo tanto, haber traído a gente de largas distancias a estos grandes santuarios. Las conexiones entre las fronteras modernas pueden probarse de otras formas. Una de las principales categorías de artefactos procedentes de los túmulos más grandes del quinto milenio en Morbihan meridional son las cuentas y colgantes de variscita (no menos de 251 cuentas en Tumiac, y 126 cuentas y 10 colgantes del Tumulus de Saint-Michel, por citar sólo dos de estos sitios). Existen canteras de esta piedra verdosa en Francia, la más cercana de ellas en Pannecé en Loire-Atlantique. El análisis compositivo de la variscita procedente de los túmulos de Carnac ha demostrado, sin embargo, que su origen está en la Península Ibérica, en Cataluña y posiblemente Huelva. Otras cuentas de collar y pendientes de variscita encontrados en Breteña procedían del noroeste de Iberia (HERBAUT Y QUERRÉ, 2004). El hecho de que se encuentren muy pocas en Francia occidental, al sur del río Loira, sugiere que el tráfico fue direccional, esto es, que se centró espe- 
4. El Gran Menhir Brisé en Locmariaquer en el sur de Bretaña. Originalmente de unos 20 metros de altura, se encuentra fragmentado en cuatro piezas. La forma elaborada de las superficies es particularmente evidente en el fragmento más grande (abajo a la derecha) / Foто:

Chris SCARRE. Fuente: DIBujo BASAdo en BaILloud ET AL., 1995
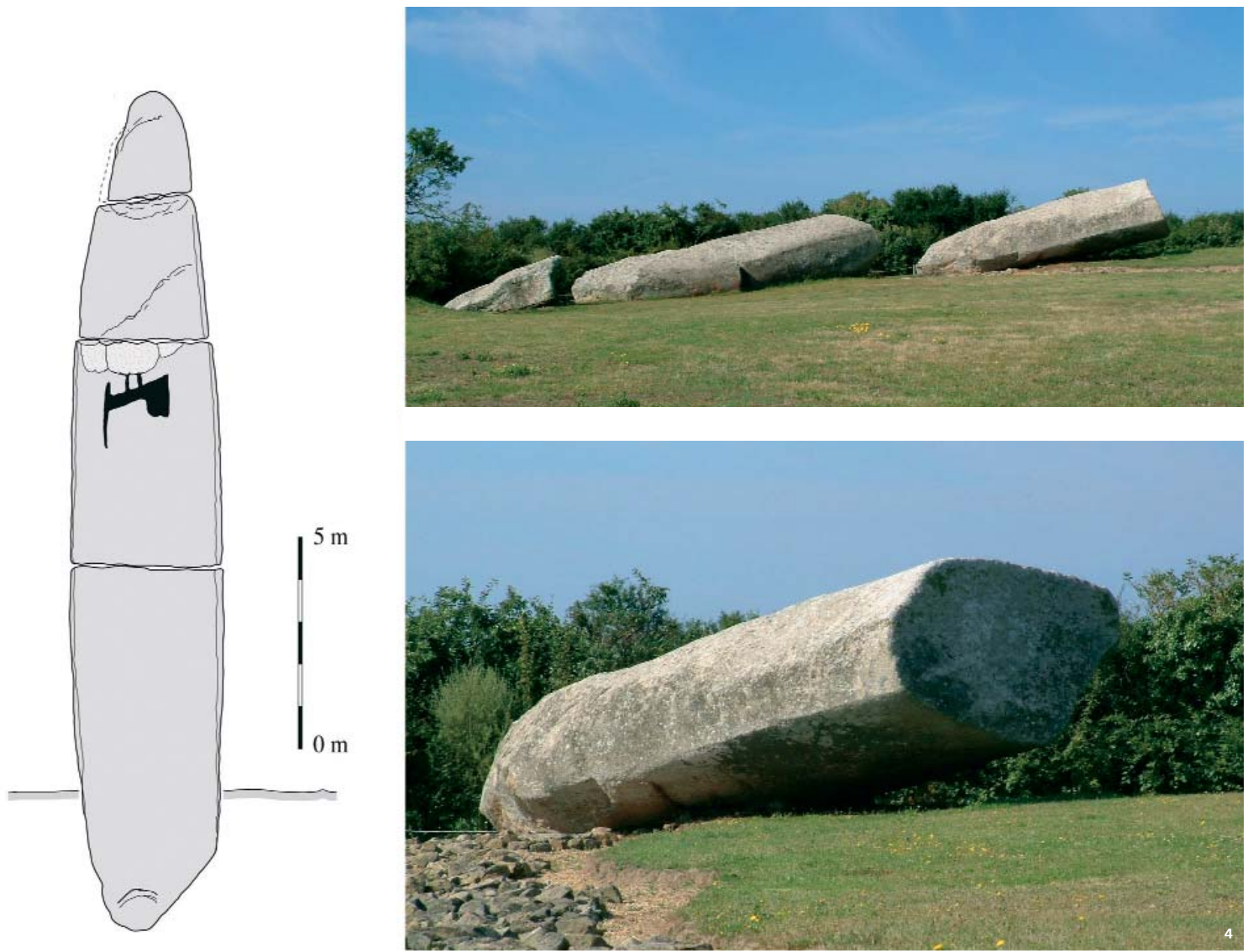

cíficamente en centros emergentes del poder sagrado o secular en Bretaña meridional. La conexión pudo perfectamente haber sido de naturaleza marítima. La estrecha relación entre Galicia y Bretaña en este período se demuestra por los hallazgos de las hachas de fibrolita en Galicia, morfológicamente idénticas a las de Galicia, y por el motivo conocido como la "Cosa" ("The Thing") tallado en las tumbas megalíticas en ambas regiones (muy significativos los ocho ejemplos tallados en el ortostatos C6, probablemente un menhir anterior, del Dolmen de Dombate, Galicia). Las interpretaciones recientes de La Cosa como cachalote nos recuerdan de nuevo el papel del mar en las conexiones interregionales (CASSEN Y VAQUERO LASTRES, 2000). Enlaces marítimos similares conectan el relativamente escaso arte megalítico de Gran Bretaña occidental y del norte (en particular, las Islas Orcadas y el norte de Gales) con el registro arqueológico del Valle de Boyne (Irlanda), que es mucho más prolífico. Es muy probable que hubiera contactos a través del mar irlandés. De hecho, es fácil suponer que la gente que labró los motivos en los ortostatos del sepulcro de Barclodiad y Gawres, en Anglesey, hubieran visto ellos mismos las tallas realizadas en las tumbas irlandesas, como las de Knowth y Dowth. El contacto con las Islas Orcadas puede observarse en la misma distribución de la cerámica "Grooved Ware" en el tercer milenio, cuando de nuevo el Valle Boyne y las Islas Orcadas eran centros importantes.

\section{CONEXIONES Y ORIGENES: ¿"PUEBLO MEGALÍTICO” O CREENCIA COMPARTIDA?}

La evidencia de conexiones entre las distintas "provincias" megalíticas del oeste y del norte de Europa plantea cuestiones significativas e importantes referentes a los orígenes de la tradición megalítica. En 1865 , cuando el barón de Bonstetten en su Essai sur les Dolmens escribió la primera interpretación genérica sobre tumbas megalíticas europeas, se vio sorprendido por su pauta de distribución que se extendía desde el 
Báltico al Mediterráneo. Él concluyó que había habido un único pueblo, asentado entre esas dos orillas, que había construido los grupos de tumbas (dólmenes), un pueblo cuyo nombre y su misma existencia habían quedado perdidos en las nieblas del tiempo prehistórico. Su distribución trazó la "gigantesca peregrinación" de un pueblo entero, como preludio a las migraciones posteriores de los pueblos históricamente conocidos como los celtas, godos y vándalos.

El concepto de Bonstetten de un "pueblo megalítico" o de una "raza megalítica" se aplicó durante la segunda mitad del siglo XIX y fue ampliamente utilizado todavía en la primera mitad del siglo XX. Muchas interpretaciones de este período incluían mapas que mostraban la distribución de monumentos megalíticos con flechas indicando la dirección de su dispersión. Bonstetten prefirió situar su origen en el norte de Europa, pero descubrimientos tales como los templos malteses pronto volvieron a dirigir la atención al Mediterráneo como el lugar preferente de origen. Gradualmente, la idea de la migración de pueblos enteros dio lugar a una opinión más matizada sobre el tipo de conexión en cuestión. Algunos sostuvieron que fueron prospectores metalúrgicos procedentes de los primeros estados del Próximo Oriente los que viajaron por mar buscando nuevas fuentes de metal para sus sociedades, ávidas de abastecimiento de metales. Otros dieron mayor relevancia al carácter claramente ritual de los monumentos megalíticos, sosteniendo que su expansión estaba relacionada con la religión. El principal defensor de esta visión, el arqueólogo australiano Gordon Childe, desarrolló la noción de los "misioneros megalíticos" que viajaban del Mediterráneo hacia el norte a lo largo de las vías marítimas atlánticas, trayendo con ellos una nueva religión que fue ligada directamente a la construcción de monumentos megalíticos (CHILDE, 1940).

Estas teorías "difusionistas" que consideraban un único origen para los monumentos megalíticos seguido de su propagación a través de amplias áreas del oeste y del norte de Europa fueron dominantes hasta los años 60 y los años 70 en los que la datación de radiocarbono proporcionó por primera vez la posibilidad de fechar los monumentos a través de técnicas científicas. Los resultados de la datación de radiocarbono revelaron que el patrón cronológico de los monumentos megalíticos no era de unos primeros monumentos mediterráneos seguidos de otros progresivamente más tardíos según se desplazaba uno hacia la fachada atlántica. Por el contrario, los primeros monumentos parecían estar situados en Bretaña, aunque en Escandinavia meridional, Irlanda y Portugal también fueron identificados núcleos tempranos de monumentos megalíticos. Los nuevos datos cronológicos fueron acompañados por una nueva agenda científica que intentó entender la construcción de los monumentos en términos sociales. Así, algunos arqueólogos, como Colin Renfrew, sostuvieron que el patrón de las dataciones del radiocarbono indicaba que los monumentos megalíticos se habían originado de forma indepen- diente en varias regiones distintas de Europa occidental aproximadamente al mismo tiempo (RENFREW, 1976). Este patrón del desarrollo convergente podía ser explicado por la presión demográfica resultante de la extensión de la agricultura en Europa. Varios de los primeros centros de tumbas megalíticas coincidían con áreas donde las comunidades de cazadores-recolectores habían sido muy numerosas y prósperas. En el sur de Escandinavia, Bretaña y Portugal, había cementerios sólo de cazadores-recolectores de la fase final del Mesolítico. Cuando la agricultura (y los agricultores), procedente desde el sudeste de Europa, alcanzó los límites occidentales y septentrionales de Europa, la carencia de más tierra para extenderse y la competencia entre los cazadores-recolectores locales generaron presiones sociales intensas que impulsaron a los primeros agricultores a construir monumentos perdurables para marcar su legitimidad y posesión de la tierra. Los procesos de este tipo, que funcionaron en paralelo a lo largo de las costas norteñas y occidentales de Europa, sirvieron para explicar los orígenes y la distribución de los monumentos megalíticos.

La teoría de orígenes independientes múltiples es sin embargo difícil de sostener dada la clara semejanza entre los monumentos megalíticos en las diversas regiones de la Europa atlántica. Los primeros agricultores no sólo construyeron los monumentos, sino que lo hicieron con materiales y formas similares, lo que sugiere fuertemente un sistema común de entendimiento o (más probable) un alto grado de conexión entre ellos. Mencionamos anteriormente la evidencia del contacto directo entre Anglesey e Irlanda, y entre Bretaña y Galicia. Otra característica de importancia es la repetición de la forma del "sepulcro de corredor y cámara" desde el Algarve hasta Escandinavia. La característica dominante de este tipo de sepulcro es la creación de un pasadizo construido en piedra que permitía un acceso continuado a la cámara durante mucho tiempo después de que la tumba hubiera sido terminada. El corredor pudo haber sido utilizado en una variedad de maneras: para introducir los nuevos cuerpos en la cámara (la mayoría, si no todas, de estas tumbas que son lugares de enterramiento colectivo a veces alberga los restos de varios cientos de individuos); para permitir el desalojo de partes esqueléticas después de que los cuerpos se hubieran descarnado (la mayor parte de los esqueletos están incompletos, dándose en algunos casos la clasificación y el amontonamiento de elementos significativos tales como los cráneos y los huesos largos); o para permitir la entrada de individuos en las tumbas para estar en comunión con los espíritus de los muertos. El valor geográfico del sepulcro de corredor sugiere un cierto sistema de ideas o de prácticas comunes que fue comunicado y compartido extensamente entre las comunidades de constructores de megalitos de Europa septentrional y occidental.

Otra característica compartida en gran parte de esta región (aunque no toda) es la orientación de la entrada de la tumba. Las investigacio- 
6. El final por el oeste de las alineaciones de Le Ménec: (a) la disposición original propuesta por Aubrey Burl, con una doble avenida acercándose a la entrada del recinto oval, (b) el plan final, con la propuesta de añadir nuevas filas de piedras en cada lado de la avenida original / FUENTE: BURL, A., 1993

nes en la Península Ibérica y Francia occidental hasta Bretaña han revelado una preferencia casi universal por la orientación de los corredores entre el sur y unos pocos grados al norte del este. Esta orientación recurrente sugiere fuertemente que las entradas de la tumba fueron alineadas hacia la posición de salida del sol; la variación (entre $180^{\circ}$ y $80^{\circ}$ ) era, en parte, la consecuencia del cambio de la posición de salida del sol en las diferentes estaciones del año. Así, se documenta que aproximadamente la mitad de la región megalítica europea comparte la disposición u orientación de los monumentos hacia la salida del sol (HOSKIN, 2001). Esto puede haber estado asociado con la idea de regeneración, o con mitologías y cosmologías prehistóricas que estuvieron directamente vinculadas con los acontecimientos solares y celestiales. La orientación hacia el orto solar se observa también más allá de esta zona, en sitios tales como Newgrange, donde el corredor largo y elevado se orientaba cuidadosamente para permitir que la luz del sol brillara a través de una "claraboya" o abertura construida en la entrada de la cámara. En este caso, sin embargo, la orientación es hacia el solsticio de invierno y no al solsticio de verano. La orientación de Newgrange asegura que este efecto se produzca solamente algunos días alrededor del solsticio de invierno, cuando los rayos de salida del sol brillan en el corredor e iluminan un adorno en triple espiral tallado en uno de los ortostatos de la parte posterior de la cámara. El simbolismo de la regeneración en la época más oscura y más fría del año sería muy impactante. Las orientaciones solares, lunares y estelares también se han relacionado con los círculos de piedra y las alineaciones de piedras. La más famosa de éstas es la orientación solar de Stonehenge. El anticuario William Stukeley observó ya en 1723 que el eje principal de Stonehenge fue alineado hacia la salida del sol en el solsticio de verano (todavía hoy día se reúnen multitudes todos los años para presenciar el evento). Sin embargo, se puede sostener el argumento de que la orientación verdadera de Stonehenge no es hacia el solsticio de pleno verano, sino en la dirección diametralmente contraria, hacia el ocaso del sol en el solsticio de invierno (CHIPPINDALE, 2004).

\section{EL DESAFÍO DE LA CRONOLOGÍA}

La cronología sigue siendo uno de los principales desafíos en nuestra comprensión de los monumentos megalíticos. Como hemos visto, fue la llegada de la datación por radiocarbono la que puso en crisis por primera vez la convicción, durante mucho tiempo mantenida, de que los monumentos megalíticos tenían su origen en la Península Ibérica o el Mediterráneo y que la tradición megalítica se había propagado desde allí hacia Europa occidental y septentrional. Sin embargo, mientras que ahora está claro que algunos de los más antiguos monumentos megalíticos se encuentran en Bretaña y Portugal, es conveniente observar que muchas de las primeras dataciones radiocarbónicas, publicadas en los años 60 y
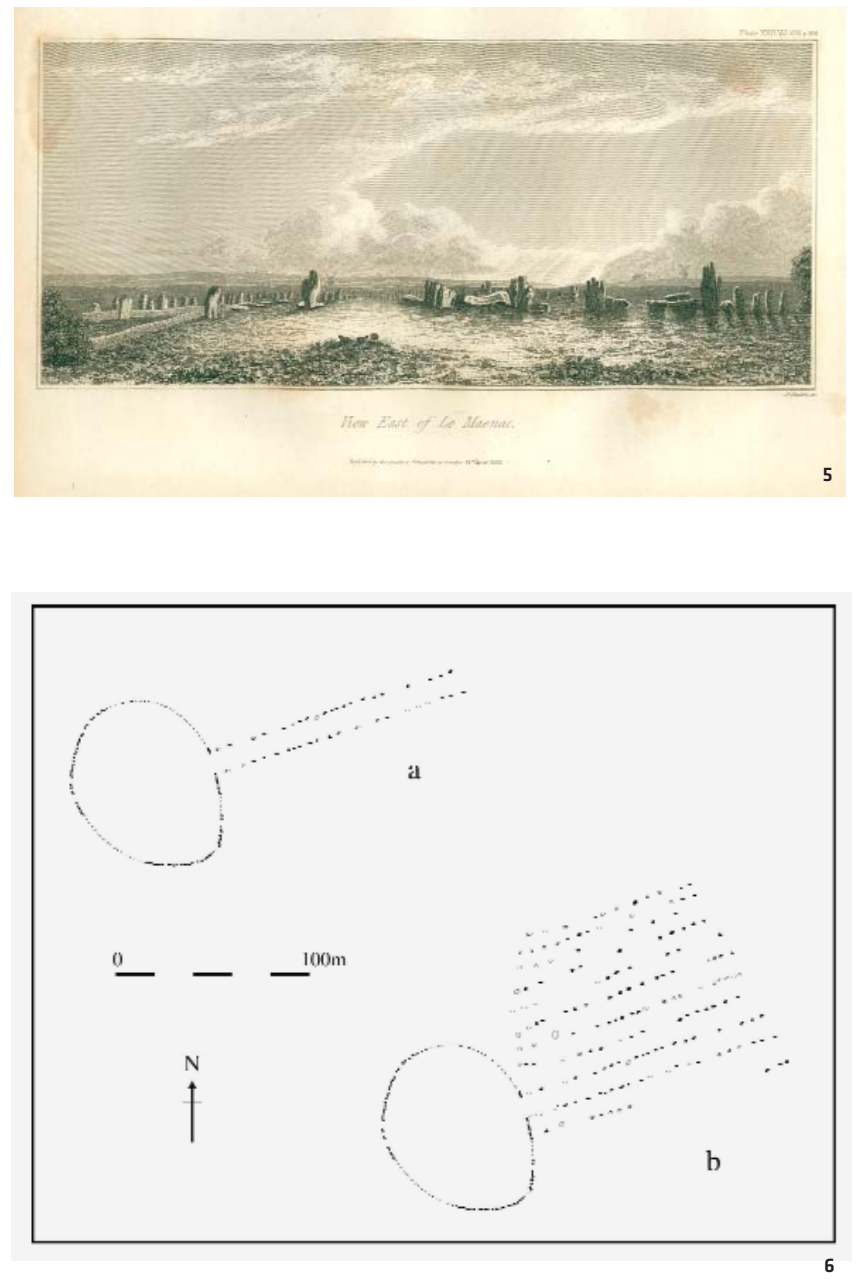

utilizadas para apoyar la hipótesis de los orígenes en Francia septentrional y el occidente de la Península Ibérica, se han desacreditado o cuestionado desde entonces. Esto incluye, en particular, la serie de dataciones para el túmulo de cámaras múltiples de Barnenez, en la costa del norte de Bretaña (imagen 7). El túmulo aloja al menos 11 sepulcros de corredor, accesibles por corredores largos que se abren en su flanco meridional. Entre ellos están los que tradicionalmente se han considerado como ejemplos clásicos de sepulcros de corredor "atlánticos" tempranos, con techumbres de falsa cúpula hechas con aparejo de mampostería y dataciones radiocarbónicas que sugieren que se construyeron en la primera mitad del quinto milenio a. de C. Lo que se fechó, sin embargo, no fue el monumento en sí mismo el carbón. Además, de un total de 13 fechas obtenidas por radiocarbono, sólo cinco cayeron dentro del período neolítico; otras eran mucho más recientes, situadas incluso en la Edad Media, lo que indica que las cámaras funerarias habían continuado siendo visitadas durante miles de años después de que fueran 


\section{Barnenez (Finistèrre)}
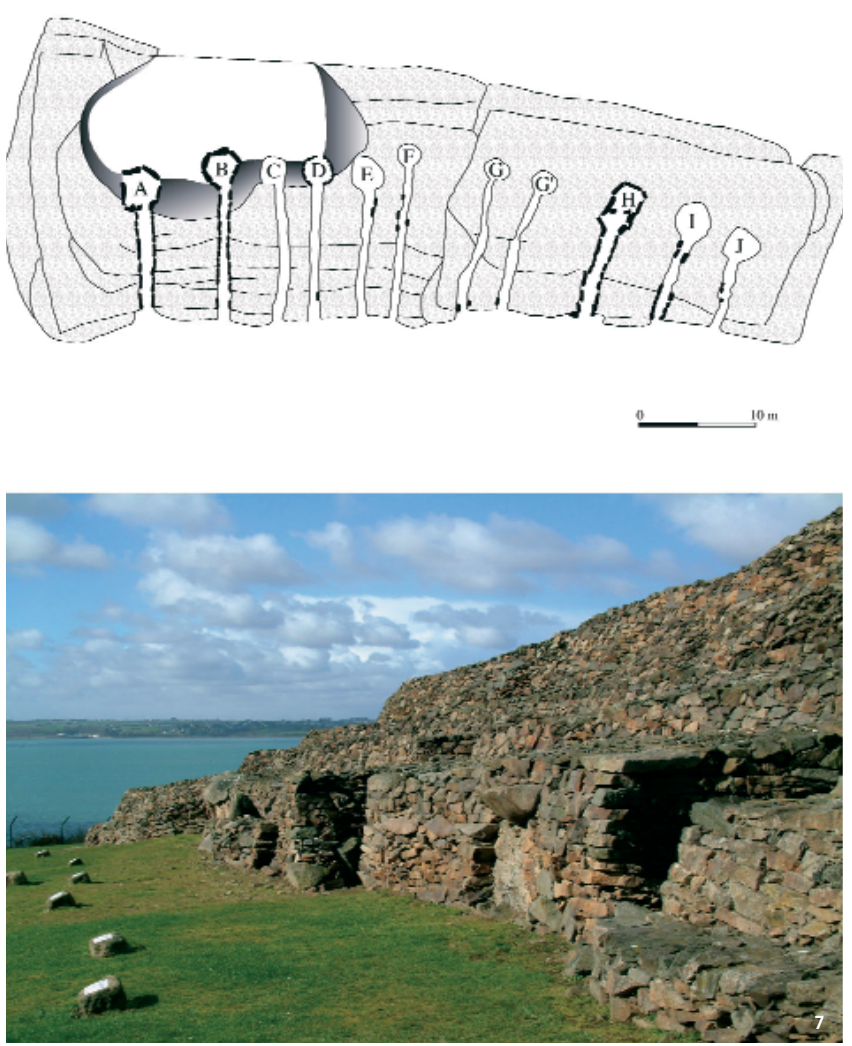

construidas. En la actualidad, no parece claro si el carbón fechado estaba asociado con seguridad con la construcción inicial (SCARRE, 2003).

El problema de fechar estos monumentos reside esencialmente en el hecho de que los métodos usados son generalmente aplicables solamente al material encontrado en asociación, y no a las estructuras propiamente. Por lo tanto, la datación radiocarbónica, que sigue siendo el método más ampliamente utilizado, se puede aplicar solamente a los materiales orgánicos. En el caso de los monumentos funerarios, en los que dentro se encuentran restos humanos, la duda viene en parte paliada por el hecho de que esos restos fechan el período inmediato (o algo posterior) en el que el monumento fue construido. Sin embargo, numerosos monumentos megalíticos de Europa occidental se encuentran en áreas geológicas ácidas donde los restos humanos raramente se han preservado. Esto ocurre, por ejemplo, en todo el noroeste de Francia, y en las áreas extensas del occidente de la Península Ibérica, incluyendo Galicia y el Alentejo portugués. En estas áreas, que contienen algunos de los monumentos megalíticos más impresionantes, la datación fiable sigue siendo unos de los principales desafíos. Este es uno de los principales problemas el caso de los menhires, ya sean individuales o agrupados en círculos y alineaciones. A veces es posible fechar carbón encontrado dentro del relleno de las fosas o agujeros de cimentación en las cuales estas piedras fueron levantadas, pero de nuevo es difícil estar por completo seguros de que ese carbón fuera contemporáneo al levantamiento de la piedra. Otras alternativas a la datación por radiocarbono, en particular la datación por luminiscencia (que determina el tiempo transcurrido desde que una superficie fuera expuesta por última vez a la luz del sol), ofrecen un cierto potencial para superar estas limitaciones. Teóricamente, la datación por luminiscencia se puede aplicar directamente a bloques de granito, permitiéndonos fijar el momento en el que sus bases fueron enterradas en la tierra, pero el método es bastante menos exacto que la datación por radiocarbono.

En circunstancias favorables, por el contrario, la cronología de los monumentos megalíticos y las actividades a ellos asociadas se pueden fijar con seguridad y precisión. Un buen ejemplo es proporcionado por las cámaras megalíticas pintadas en el noreste de la Península Ibérica, donde la datación radiocarbónica por AMS ha permitido fechar cantidades minúsculas de carbón de leña dentro de los motivos pintados en las paredes de la cámara (STEELMAN et al., 2005). Otro ejemplo es suministrado por la media docena de sepulcros de corredor daneses, en los que se puso corteza de abedul doblada entre las hiladas de mampostería que llenaron los espacios entre los ortostatos megalíticos. Se puede fechar por radiocarbono la corteza de abedul, lo que demuestra que estas tumbas fueron construidas en un periodo muy corto de tiempo a finales del cuarto milenio a. de C. (DEHN Y HANSEN, 2006). De hecho, parece que varios miles de sepulcros de corredor daneses de diseño muy similar fueron construidos dentro de un período de sólo 200 años. Es posible que en muchas áreas de Europa occidental las tumbas megalíticas que sobreviven fueran construidas en relativamente breves e intensos periodos de actividad. Es solamente nuestra incapacidad para fecharlas exactamente lo que nos impide la identificación de estos patrones.

Sin embargo, muchas tumbas con cámaras y otros monumentos megalíticos no eran el producto de episodios singulares de construcción, sino el resultado de actividades que se extendían durante décadas o siglos. Las excavaciones recientes demuestran cada vez con más frecuencia cómo las tumbas se construían a menudo lugares donde anteriormente había habido actividad. En algunos casos, una tumba pudo cubrir los restos de una casa anterior. En estos casos, la gente enterrada en la tumba pudo haber sido la que había vivido antes en esa vivienda o había tenido cierta vinculación cercana con ella. En otros casos, las tumbas incorporaron trazas de actividad funeraria anterior. En Gran Bretaña y el norte de Europa, una categoría importante de monumentos son los túmulos largos que cubren los restos de una cámara funeraria de madera. La cámara de madera sirvió como estructura funeraria para albergar los restos humanos antes de que el túmulo fuera construido sobre ésta; general- 
mente, después de que la estructura de madera se quemara intencionadamente. En estos casos, el túmulo largo actuaba como monumento conmemorativo para la actividad funeraria que había precedido a su construcción. En algunos casos, como en Bygholm Norremark en Dinamarca o Wayland's Smithy en Gran Bretaña meridional, el túmulo largo que cubre el sitio de la estructura anterior de madera tenía su propia cámara de enterramiento, esta vez de construcción megalítica.

Recientemente, una serie de túmulos largos de Gran Bretaña meridional ha sido el tema de un programa intensivo de datación de carbones y restos humanos. Hasta 44 dataciones fueron obtenidas para cada sitio, permitiendo reconstruir la cronología detallada de la construcción, modificación y actividad funeraria. Los resultados (analizados con estadística Bayesiana) revelaron un patrón de acontecimientos comprendido en el tiempo de dos o tres generaciones (BAYLISS Y WHITTLE, 2007). Estas secuencias detalladas nos recuerdan que los monumentos megalíticos y los túmulos largos de tierra fueron construidos por individuos reales con antecedentes familiares propios, y que un monumento construido por una generación pudo ser modificado o embellecido por sus hijos o nietos. Tales estudios ayudan a rescatar los monumentos megalíticos de la oscuridad de un pasado despersonalizado.

\section{MONUMENTOS MEGALITICOS, CUERPOS HUMANOS Y SIMBOLISMO DE LAS PIEDRAS}

La cronología no es el único desafío al que se enfrentan los arqueólogos que intentan hoy entender los monumentos megalíticos. Otra cuestión clave es la relación de estos monumentos con el cuerpo humano. En el caso de las tumbas con cámaras en áreas de suelos alcalinos, la conexión es visible y directa en un sentido concreto: a través de los restos de esqueletos preservados enterrados en la tumba. Muchas cámaras megalíticas fueron diseñadas y pensadas como enterramientos colectivos, lo cual plantea preguntas sobre la naturaleza de la sociedad, el simbolismo funerario y los sistemas prehistóricos de creencias. En algunos casos, está claro que los cuerpos fueron depositados sucesivamente dentro de la cámara y se dejaron más o menos sin tocar a partir de entonces. Más numerosos y llamativos son los ejemplos en los que el material óseo está incompleto, abarcando elementos de docenas o aún de centenares de individuos, ninguno de cuyos esqueletos se encuentra íntegro en su totalidad. Puede ser que la retirada selectiva de huesos de cámaras de enterramiento fuera una práctica extendida, y el descubrimiento de huesos aislados en otros contextos (sea asentamientos o recintos) podría atestiguar la conservación de huesos como reliquias de difuntos.

Junto a los restos humanos enterrados dentro de las tumbas con cámaras está la cuestión del antropomorfismo potencial de los bloques me- galíticos. Durante más de doscientos años, los anticuarios y los arqueólogos han reflexionado sobre el significado de la construcción megalítica. ¿Por qué se emplearon piedras de tamaño tan extravagante cuando las pequeñas piedras en hiladas regulares de mampostería habrían sido más fáciles de manipular? Se podría proponer un gran número de explicaciones, y entre ellas se encuentra la de que algunos de los bloques monolíticos, quizás muchos, eran considerados en cierta manera representaciones de seres humanos. Esto puede ilustrarse a partir del gran número de piedras que se tallaron con características humanas o se modelaron con semejanza a la forma humana. Estas piedras eran originalmente menhires exentos, aunque muchos de ellos fueron incorporados más adelante a la estructura de tumbas con cámaras. La gran losa "con hombros" que forma la piedra del suelo del túmulo del sepulcro de corredor Petit Mont // en Bretaña meridional es una de las ilustraciones más gráficas de este proceso: la "cabeza" redondeada separada del "cuerpo" por curvas cóncavas que terminaban en "hombros" bien definidos. La piedra estuvo originalmente en un extremo del túmulo de tierra que se encontraba bajo el túmulo del sepulcro de corredor hoy visible. Otras losas de piedra en Bretaña y la cuenca de París se tallan con motivos pareados que se pueden interpretar como pechos femeninos, y éstos se pueden comparar con el menhir estatua completo de Le Câtel en Guernesey, con cabeza, hombros, collar y pechos (imagen 8).

¿Podría ser que la tradición megalítica tuviera sus orígenes en la tradición de tratar a ciertos bloques megalíticos como si fueran "humanos"? Esta idea toma peso al examinar la tradición popular que ha atribuido habitualmente cualidades humanas a los monolitos megalíticos. Así, como vimos antes, el círculo de piedras Merry Maidens en Cornualles era interpretado como un grupo de mujeres jóvenes atolondradas convertidas en piedra por bailar en el Sabbath. Asimismo, las hileras de piedras de Carnac a veces han sido vistas como soldados romanos petrificados a través de la intervención divina para frustrar su persecución de Saint Cornély. Los datos etnográficos también apoyan la idea de que los monolitos megalíticos son considerados a veces representaciones de personas. El pueblo merina de Madagascar, por ejemplo, llama a ese tipo de piedras valotahy o "piedras-hombre".

Además de las cualidades humanas que han sido atribuidas a los menhires y monolitos, debemos también considerar la conexión con lugares de especial importancia en el paisaje. La mayor parte de los monumentos megalíticos están formados por materiales traídos de áreas próximas. En la planicie de norte Europa, por ejemplo, donde los monumentos fueron construidos a partir de bloques "erráticos" desplazados por glaciares, los campos de bloques pétreos de los que proviene el material se encuentran normalmente en un radio de medio kilómetro de la zona de construcción. Igualmente, sin embargo, hay casos en los que sin ninguna razón aparente, los bloques megalíticos fueron traídos desde distancias 

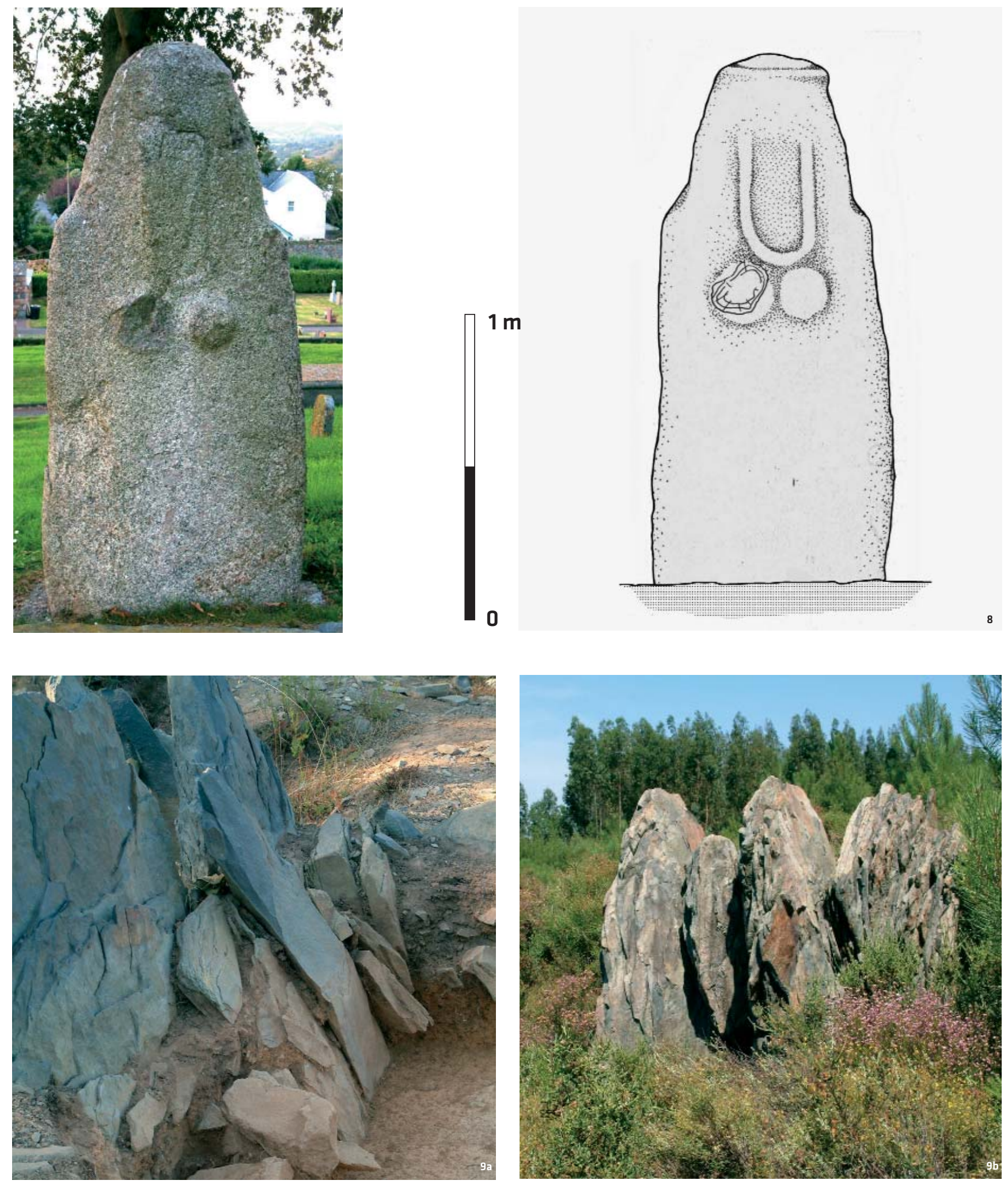
mucho más grandes. Las bluestones de Stonehenge son uno de los ejemplos más claros de esto, pero no el único. En el Vale de Rodrigo cerca de Évora, por ejemplo, tres impresionantes sepulcros de corredor (más uno hoy destruido) fueron construidos en gran parte de material de la zona, pero incorporando bloques de granodiorita porfírica traídos desde 8 km o más. Estos bloques no poseían ninguna cualidad especial para la ingeniería, y de hecho entre las piedras de cobertura ("las cobijas") de la Tumba 2 de Vale de Rodrigo hay sólo una de granodiorita porfírica que se ha fracturado por el peso del monumento, pero debe haber habido algo especial en el lugar de origen que dio a esos bloques una cierta importancia (KALB, 1996; LARSSON, 1998).

Por lo tanto, para entender los monumentos megalíticos debemos tener en consideración el paisaje en el que éstos fueron construidos. Hoy, siglos de limpiezas y de agricultura han eliminado los bloques y afloramientos de piedras que una vez se esparcían por las principales áreas de monumentos megalíticos. El lugar del que procedían los bloques de piedra era frecuentemente un elemento llamativo en el paisaje. Los trabajos recientes en Anta da Lajinha, en el interior de Portugal, son un buen ejemplo. Los ortostatos de la pequeña cámara de enterramiento que han sobrevivido han sido traídos de los afloramientos columnares de esquisto que atraviesan las laderas cercanas (imagen 9a y b). Éstas fueron las mejores fuentes locales de losas megalíticas y monumentos naturales destacados en sí mismos, características inconfundibles de un paisaje local que pudo haber poseído todas las supersticiones y asociaciones que están documentadas en el folclore y la etnografía de manera tan persuasiva. Por lo tanto, la tradición megalítica no fue meramente arquitectura oportunista y primitiva, obra de gente que no sabía cómo construir con mampostería de materiales de dimensiones más manejables. Se trataba de una elección concreta, vinculada a creencias sobre el paisaje, sobre el simbolismo de la piedra, y tal vez de los atributos humanos encerrados en las grandes losas monolíticas.

\section{Bibliografía}

BAILLOUD, G.; BOUJOT, C.; CASSEN, S.; LE ROUX, C-T. (1995) Carnac. Les premières architectures de pierre. Paris: CNRS, 1995

BAYLISS, A.; WHITTLE, A. (ed.) (2007) Histories of the dead: building chronologies for five southern British long barrows. Cambridge Archaeological Journal, 17 (1), 2007 (supplement)

BURL, A. (1993) From Carnac to Callanish. The Prehistoric Stone Rows and Avenues of Britain, Ireland and Brittany. New Haven: Yale University Press, 1993

CASSEN, S. ; VAQUERO LASTRES, J. (2000) La forme d'une chose. En Cassen, S. (ed.) Éléments d'Architecture. Exploration d'un Tertre Funéraire à Lannec er Gadouer (Erdeven, Morbihan). Constructions et Reconstructions dans le Néolithique Morbihannais. Propositions pour une Lecture Symbolique. Chauvigny: Association des Publications Chauvinoises, 2000, pp. 61 1-56

CHILDE, V. G. (1940) Prehistoric Communities of the British Isles. London: Chambers, 1940

CHIPPINDALE, C. (2004) Stonehenge Complete. London: Thames \& Hudson, 2004

DARVILL, T. (2006) Stonehenge. The Biography of a Landscape. Stroud: Tempus, 2006
DEANE, J. B. (1834) Observations on Dracontia. Archaeologia: Or Miscellaneous Tracts Relating to Antiquity, 25, 1834, pp. 188-229

DEHN, T.; HANSEN, S. I. (2006) Birch bark in Danish passage graves. Journal of Danish Archaeology, 14, 2006, pp. 23-44

GIOT, P. R. (1987) Barnenez, Carn, Guennoc. Rennes: Travaux du Laboratoire d'Anthropologie, Préhis-toire, Protohistoire et Quater naire Armoricains, 1987

HERBAUT, F.; QUERRÉ, G. (2004) La parure néolithique en variscite dans le sud de l'Armorique. Bulletin de la Société Préhistorique Française, 101, 2004, pp. 497-520

HOSKIN, M. (2001) Tombs, Temples and Their Orientations. A New Perspective on Mediterranean Prehistory. Bognor Regis: Ocarina Books

KALB, P. (1996) Megalith-building, stone transport and territorial markers: evidence from the Vale de Rodrigo, Évora, south Portugal. Antiquity, 70, 1996, pp. 683-5

LARSSON, L. (1998) Rock, stone and mentality. Stones that unite, stones that subjugate - a megalithic tomb in the Vale de Rodrigo, southern Portugal. KVHAA Konferenser, 40, 1998, pp. 137-155

LE ROUX, C.T. (1997) Et voguent les menhirs? Bulletin d'Information de l'Association Manche-Atlantique pour la Recherche Archéologique dans les lles, 10, 1997, pp. 5-8
RENFREW, C. (1976) Megaliths, territories and populations. En De Laet, S. J. (ed.) Acculturation and Continuity in Atlantic Europe. Brugge: De Tempel, 1976, pp. 198-220

RICHARDS, J.; WHITBY, M. (1997) The engineering of Stonehenge. En Cunliffe, B.; Renfrew, C. (ed.) Science and Stonehenge. London: Oxford University Press, 1997, pp. 231-256

SCARRE, C.; ARIAS, P.; BURENHULT, G.; FANO, M. A.; OOSTERBEEK, L.; SCHULTING, R.; SHERIDAN, A.; WHITTLE, A. (2003) Megalithic chronologies. En Burenhult, G. (ed.) Stones and Bones. Formal Disposal of the Dead in Atlantic Europe During the Mesolithic-Neolithic Interface 6000-3000BC. Oxford: Archaeopress, 2003, pp. 65-111

SCARRE, C. (2007) The Megalithic Monuments of Britain and Ireland. London \& New York: Thames \& Hudson, 2007

SHEE TWOHIG, E. (1981) The Megalithic Art of Western Europe. Oxford: Clarendon Press, 1981

STEELMAN, K. L.; CARRERA RAMÍREZ, F.; FÁBREGAS VALCARCE, R.; GUILDERSON, T.; ROWE, M. W. (2005) Direct radiocarbon dating of megalithic paints from northwest Iberia. Antiquity, 79, 2005, pp. 379-89 